\title{
The Impact of Information Technology Management, Training and Strategy Management on Organizational Performance of Sharjah Police
}

\author{
Abdulla Awadh Abdulla Abdulhabib ${ }^{1}$, Hassan Saleh Al-Dhaafri ${ }^{2}$ \\ ${ }^{1}$ Management Science University (MSU), Malaysia, Ministry of Interior, Sharjah Police, U.A.E \\ ${ }^{2}$ Assistant Professor, University of Dubai, Dubai Police, Dubai, United Arab Emirates \\ Correspondence: Abdulla Awadh Abdulla Abdulhabib, Management Science University (MSU), Malaysia, \\ Ministry of Interior, Sharjah Police, U.A.E.
}

Received: October 2, 2018

Accepted: November 1, 2018

Online Published: November 2, 2018

doi:10.5539/ibr.v11n12p1

URL: https://doi.org/10.5539/ibr.v11n12p1

\begin{abstract}
The study mainly aims at investigating the impact that happens to the organizational performance as an impact of utilizing both information technology management and training. In-depth investigation of literature indicates the necessity of the proposal of the current research. The current study has utilized various theories including Knowledge Based View (KBV) and Resource Based View of the firm (RBV) so as to achieve the main purpose of the research. It also aimed at examining the impact of IT management and training on the performance of the organization. The study used a questionnaire as a tool. The researcher distributed a number of 341 questionnaires randomly on some department of the police in Sharjah. When the questionnaires were filled, the researcher used SPSS system in order to accurately analyze the results. The study concluded that the organizational performance of the Sharjah police has been positively affected by using information technology management. In addition, the research shows that it is essential to utilize on information technology management, training and strategy management on order to affect the performance of the organization successfully.
\end{abstract}

Keywords: information technology, training, strategy, performance

\section{Introduction}

\subsection{Overview of Sharjah Police}

It was till the year 1967 that the Sharjah Police was first begun as General Security Police force in the emirate of Sharjah. The decree of establishing the Sharjah Police was issued by his highness the late Sheikh Khalid Bin Mohammed Al Qasimi. Initially, it was established as a local organization to keep safety and security in the emirate. It was supervised by the general security chief and it had affiliations with the ruler of Sharjah. Two of the qualified Citizens in Sharjah were appointed; Colonel Abdullah juma Al-Saree and Mr. Burner from Oman British Coast to train and supervise the force. The Sharjah Police was integrated in the United Arab Federal Police system in 1971 based on the decree of his highness Sheikh Dr. Sultan Bin Mohammed Al-Qasimi to be in the federal system. Currently, there are some various departments in the General Directorate of the Sharjah Police. The departments are specialized in numerous police and security fields and other units in co-operation with the police directorate in the east region.

According to the reports issued by the police in Sharjah, the decision number 3 of 1995 was issued to support the Sharjah Police to include a number of 9 departments and become a general directorate. The ministerial decision number (298) was issued in 1996 and it rearranged the Sharjah police and established its headquarters. As a result, the police organization in Sharjah was qualitatively transformed and its performance became more modern and worked in a long with the present changes in order to maintain more safety and security in the emirate. It is the responsibility of the police to implement the most suitable styles that are appropriate to overcome any type of crime.

\section{Organizational Performance}

Due to the importance of the organizational performance in incurring development in the organization as well as their effectiveness and competitiveness, research has focused mainly on the field of humanity. For example, it 
was noted that the most basic variable that most studies focused on is the organizational performance (Combs, Crook, Shook, David, Ketchen, 2005). In addition, both academics and practioners have studied the aspect of organizational behavior to examine the antecedents and processes for enhancing the outcomes of the organization and its performance levels ((Jing \& Avery, 2008). Furthermore, according to Hart (1991), not many organizations have formal processes to handle the succession of management. For example, both Davisand Nosal, ( 2009) state that it was reported in 2008 by the National Association of Corporate Directors that about 42 percent of the surveyed companies could not generate the plan of the CEO succession.

In addition , it was also stated that ((Carroll, 1984; Haveman, 1993; Haveman \& Khaire, 2004) the transitions of management has been used to optimize the performance of the organization , breach the interpersonal relationships inside the organization (Grusky, 1963) and also breach the strategy of the organization (Virany et al., 1992; Wiersema, 1992).

\subsection{Performance of Public Organization}

According to Osborne and Gaebler, (1992), there has been consistent focus by the public sector on both effectiveness and efficiency. The basic goal is to enhance the performance of the organization and achieve its objectives. It also places clarity on the resources to improve the management accessibility as well as information and quality content (De Waal, 2010). It also aims at aligning the resources with the budget cycle.

In addition, according to Ashour (2004), it is clear that the governments are always exerting effort to obtain maximum performance regarding the use of the public resources, co-operation of the citizens , the satisfaction of the customers, the outcomes of the initiatives, accountability, the prevention of corruption, integrity and transparency. These aspects are effective in protecting and supporting the role of the government and the public sector to provide the main development and services.

Kanji and Sa (2007), state that the measurement of the performance of the organization lies mainly in the core of the processes of management that require to assess whether the strategic objectives are achieved and also whether it is possible to employ solutions to the issues. Moreover, previous studies (Morgan \& Murgatroyd, 1994) show that currently performance measurements are used by the public organizations so as to achieve value for money and also facilitate the quality of service.

\subsection{The Definition of Organizational Performance}

Sink and Tuttle (1989) indicate that Innovation, effectiveness, productivity, efficiency, profitability and quality are the six different performance conditions that are related to the performance of the organization. In spite of the various studies that were carried out to examine the performance of the organization, the exact definition of it has not yet been reached and as Ford \& Schllenberg, 1982; Johannesen, Olaisen \& Olsen, 1999 indicate , there should be a consensus to reach its universal definition among the authors and researchers.

The performance of companies was examined in some studies (Bergh \& Lim, 2008; Tsai, 2001; Yeoh, 2009) focusing mainly on the performance of the organization and the absorptive capacity. The studies found out that there was a significant relationship between the absorptive capacity and the performance of the organization. The study model shows that both financial performance and innovative performance in the light of transfer of knowledge among companies and their competitive advantage.

\subsection{Organizational Performance Measurement}

As indicated by many studies (Demirbag, Tatoglu, Tekinkus \& Zaim, 2006), the measurement of the organizational performance is essential as it is used to enhance the effectiveness of the organizational management. Other studies (Kanji \& Sa, 2006) also stress its importance for promoting and communicating the awareness of the employees to make the organizational performance much better. I

Deming (1986) illustrates that it is important to measure a thing in order to improve it and is what exactly applies to measuring the performance of the organization. Some studies (Gadenne \& Sharma, 2002; Madu, Kuei \& Jacob, 1996) also show that the measurement of the organizational performance is a necessity to find out how effective are the level of the resources in business management. In addition, what is more important is that traditional the financial measurement indicators were used to measure the organizational performance. Some studies (Demirbag, Koh, Tatoglu \& Zaim, 2006) also indicate that the financial indicators had some weaknesses and it is much better to use both financial and non-financial indicators to measure the organizational performance. As previously discussed, the use of the traditional performance measurement was mainly built on the financial measurement indicators that include many aspects such as return on investment, debit, profit and sales. However, in the present dynamic business environment, these indicators are considered insufficient. This also points out the requirement for using non-financial measures for organizational performance as indicated by some previous 
studies (Johnson, 1983; Kaplan, 1984). Moreover, Burns (1998) show that financial measures are not enough for the firm to generate its profit and increase its capability and ability.

\section{Training}

The skills and the knowledge of the employees working in any organization are essential and they improve the competitiveness of the organizational performance. In addition, the contribution of HRM department in improving the performance of the organization is evident.

In any organization, the knowledge and skills of the employees are increasing in importance in terms of performance competitiveness. Some studies (Salas \& Cannon-Bowers, 2001) that both practioners and scholars appreciate the role of HRM department in improving the performance of the organization. This makes it a priority for the organizations to invest and focus on the training of its employees because this will positively contribute to the organizational performance. In addition, in the present world, it has been a solid fact that human resources are a significant source of competitive advantage and it plays an effective role in the knowledge-based economy that is going through a shift. Furthermore, HRM has an evident impact on other factors in the organization such as corporate financial performance and productivity. For example, many studies Huselid (1995), Delery and Doty (1996), Boselie, Dietz and boon (2005) and Combs, Liu, Hall \& Ketchen (2006) stress the importance of these factors for the improvement of the organization. However, these studies the focus of these studies was on the field of manufacturing in the West (the U.K and the United States of America). Although it is true that there is a positive relationship between the organizational performance and HRM, there is still a need for some empirical studies (Gerhart (2005), Ericksen \& Dyer, 2005; Wright, Gardner \& Moyniban, 2003) to point out this relationship. In the service sector, the need for highlighting this relationship is pronounced, but some studies (Sisson, 1993; Lucas, 1996; Hoque, 1999a) indicate that it is highly neglected in the HRM research because it is heterogeneous and it constitutes of hospitality businesses, retailing firms and retailing transport.

However, Ng \& Cardie, 2003; Nigam \& Ghani, 2000; Zhang (2004), indicate that better performance can be produced by random feature splitting even if it is compared to self-training in the classification of the topic text field and the NPL. Many studies (Aguinis \& Kraiger, 2009; Noe, 2008; Saks \& Belcourt, 2006; van Eerde, Tang \& Talbot, 2008) show that training is considered one of the top ways that can motivate the human capital. Wright, Dunford \& Snell (2001) illustrate that training is important in aligning the competencies of the individuals and the strategies that are required in an organization. the current study views professional training as support activities of formal training and initiatives that are created by the organization in order to increase the opportunity for the preparation and also the development of HR. these opportunities contribute positively to the improvement of skills, practices , the disposition and the knowledge of the employees. Russ-Eft et al., (2010) show that the process of training transfer involves knowledge, practices and skills that workers learn during their training.

\subsection{Training Definition}

There are also other definitions to training. Beardwell and Holden (2001) define traing as the process that is planned in order to modify skills, behavior, knowledge and attitudes of the employees through the use of experience. The main goal of training is to achieve effective performance of an activity as a whole. The main goal is to improve the abilities of the workers to fulfill the requirements of the organization. this exact definition highlights the relationship that exists between planning process and training. Training is regarded as a planning activity that helps to modify the skills of the employee through learning and experience.

It is evidenced by Savage, Forestier, Withers, Tien and Pannell (2011), Savage et al. (2015), Tien, Jung, Rizoli, Acharya \& Mac Donald (2008) that during the process of training, it is essential to analyze the acquisition of the skills based on the performance of combat causality care skills. The use of simulators (SIM) and live tissue (LT) are used in training. However, there is little information about how the acquisition of skills is affected by the training morality. In addition, Flippo (1984) describes training as the process of optimizing the skills of the employees on a performing task as well as attitudes, rules, concepts and systematic acquisition of silks that lead to better performance in a different environment of work. Chiaburu and Tekleab (2005) define training as a kind of intervention that is used in order to improve the performance determinants of the job.

\subsection{Objectives of Training}

Firstly, an objective links the capabilities of skills that employees have and what they have acquired after receiving the training. Mainly, the objective of training is decidied prior training in order to determine what the employees are going to learn. There are different topics that generally cover the objectives: 
- It is expected that the trainees will be able to provide full description of the requirements of control strategy and an explanation of precursor control process after they receive the training.

- It is also expected that after training they will licit or elicit the uses of precursors as indicated in Tables I and II of U.N. Convention, 1988.

- They trainees will also have the ability to use precursor identification field test kit in order to examine suspect substances.

- The trainees will also be able to determine and prevent cases of diversion of precursor chemicals for illicit use purposes, after they complete their training.

The productivity of the employees and their performance is greatly improved after they complete their training. That is why; the companies make use of training as an effective tool to manage risks that can result from the new products, technologies and markets. Regarding this, training is also used and invested by nations that are developing. Blandy et al., (2000), states that the performance of companies is significantly improved by the use of training. This shows the importance of training for the improvement of the employees and stresses the importance of increasing the daily hours of training as a kind of investment in the companies.

\subsection{Key Strategies of Training}

Kelley (2011) refers to Key Strategies Rating Questionnaire (KSRQ) as the measurements that gauges the acquisition of the individuals of intermediate psychotherapy intervention strategies. In addition, Workman and Lee (2004) had a look into the lack or the existence of changes and cultural differences in the spatial professional capabilities after the employees receive their training. They carried out interviews with the participants and stressed the importance of keeping in mind the strategies when they give answers.

Motivation is considered as a very important factor in the performance of the employees and training is one of the elements that have an effect on motivating the employees. Is is also found out that training affects the engagement $f$ the employees in the achievement of the entire organization goals.

Lemaire and Lecacheur (2010) carried out a study to find out the importance of training. They examined used trials involving instruction to switch and voluntary switching to examine the use of varying arithmetic strategies. In both cases, it was found out that the employees preferred switching strategies. In addition, with the simple tasks, the performance dipped. In addition, a study by Xetal showed that the respondents had the chance to select the most preferable strategies using the same strategies in two problems that follow each other.

\subsection{Adopting Feedback Specificity during Training}

Previous research (Pea, 2004; Reiser, 2004) revealed that there can be a gradual change in the suitability of the feedback content. It means that providing feedback at relevant times may to an enhanced and better performance. Using adaptive feedback in SBT can be used as an example to show that change on an effective manner. Test scores, error rates, success rates and domain-specific knowledge tests are some of the strategies that can be used to measure the competency of the individual performance. It depends on the person and his experience of personalized feedback when taking the adaptive feedback.

\subsection{Training and Organizational Performance}

Many authors have examined the relationship of performance and the training organizations. They used Ubeda-Garcia, Marco-Lajara, Sabater-Sempere and Garcia-Lillo (2013). The study used a quantitative method and it focused mainly on the relationship between training and performance in the case of Spanish firms. The findings of these studies found a positive relationship between the performance of the firms and the training that employees receive.

Four different ways, including Morley, Slavic, Poor and Berber (2016), were used to find the effect of training on performance. The measurement of training consisted of absolute measures that focused on the training that the employees received, content measures which involves the type of training that the employees received, the emphasis measure which focuse don the significance of training and the absolute measures which included the level of training that the employees received.

\subsection{Training in Middle East/UAE}

Overall, the huge amounts of petrol led to the increase in the training levels in the countries and it contributed to the improvement in the infrastructure of the region. These huge amounts of money led to the rise in the investment and numerous numbers of companies to do business and invest. These companies included both private and public organizations. In addition, these organizations have implemented the best practices and this 
contributed to the significant development in the whole region. The period of the $80 \mathrm{~s}$ was the decade of the administrative development (Zoubi, 1982).

\section{Strategy Management}

\subsection{Strategy of Business}

Outram (2013) revealed that the shift in the business context had resulted in changes over the past decade to tackle the changes in the role of management. In addition, Christensen (1997) showed that although the organizations adopted strategies that are in alignment to the market, there is still a lack to the new technologies that emerged or were adopted.

\subsection{Definition of Strategy}

Bruce and Langdon (2000) define the word strategy as the art of planning military activities and operations during the war. Matloff (1996) defines the word Strategy as a word that comes from the Greek word, 'stratos'. This Greek word means a person who is an army leader. The origin of the word goes back to the 18th century. In addition, Kaplan and Norton (2004) describe strategy as a group of activities that organizations use in order to make a niche in the market. MC Keown (2012) consider strategy as a future shaper.

\subsection{Concept of Strategy}

Porter (2008) explains that there are five forces including new entrants, substitutes, powerful suppliers, strong rivals and savvy customers that are used in the creation of strategy in a dynamic environment. In a more specific way, the customers are always in a search of low prices and top deals.

On the other hand, Nivern (2006) has proposed four main factors that are obstacles to the execution of an effective strategy and hinder resources, management, people and even the right vision. The strength of the barrier will be higher and more intense when the employees are unable to understand the strategy well.

\section{Information Technology Management}

In 1988, there was an emphasis by the network of the schools of public policy, affairs and Administration (NASPAA) to train the graduate students on information systems during the programs in public management. The main aim of doing this was to implement a shift in the outcome and the mission without minimizing the importance of IT training in the public administration curricula. Dawes (2004) states that the effect of It on the government requires the managers to work in the IS processes and to be over encompassing.

Dhar and Sundararajan (2007) state that the sustained increase in the capability of tackling the complexity is the technological variant which makes use of the modular layers on technology. it is also essential that public managers can understand how such ability can support models of organizations and also generate capabilities that were not existing before.

Candice, Sandra and John, 1998; Sife, Lwonga and Sanga, ( 2007) illustrate that learning and education is enhanced and supported by the use of It in e-learning and it also provides different strategies of learning and applications for the acquisitions of skills and exchange of information. Although there is a range of existing technologies, instructors still use training in the classrooms. However, new collaborative training systems, simulations, virtual training and self-paced e learning are used and planned by the organizations. The reality is that avout $38 \%$ of 6the firms have been using e learning and virtual system use. There are seven common elements that E-learning definition comprises through different taxonomies. These seven common elements are communication, information collection, IT Use, resources and tools, programing and taking on a more expensive view and network use. Russel and Sellman (2007) to compare the measures of Cyber and IT carried out a comparison. They compared them against several technical criteria and also their definition. It was found out that neither of them covered the whole aspects of the previously working conditions

\subsection{Definition of Technology}

Hew and Brush (2007) stated that education does not have clear definition of technology that is integrated in education. They pointed out that other previous studies gave definition to technology in education. These three perspectives are relating to the development of pupil's skills, relating to efficiency and quality assurance of the activities and relating to the ways in which new ICT can be used by the teaching in school activities.

However, Mergel (2011) shows that extensive use of It in public firms, the public values and combination of technologies advancement require urgently IT conceptualization. This will lead to the improvement of performance through the use of IT. 


\subsection{Competence and IT Competence}

The concept of competence appeared in the 1970 ( McClelland , 1973) and it was used to refer to the sets of qualities or skills that the individuals have and can be manipulated by the field of psychology as an indicator that shows the levels of job performance. Macaulay \& Lawton (2006) state that there is currently a stress on the competence that combines both management development and moral psychology. Currently, most of the public agencies have been working on developing competencies that are job-related in order to offer guidance, evaluation of the employees' performance, hiring and training. Bowman, West \& Beck (2014) and Virtanen, (2000). As explained in the previous studies, there is an ethical element in the competence which reflects the qualities of morality and virtue.

\subsection{IT Competence for Public IT Managers}

The core competence of the It managers is their attributes, knowledge and skills. However, this is not the only basic difference in their IT competence.in many cases, there is a rotation in the senior level of management in several functional departments in the organizations. One of the examples is in South Korea. Bassllier et al, (2001) and Layne ad Lee (2001) revealed that this was useful to the managers to consider organizations that are close to a group of processes that help in understanding the power of transformation in IT.

\subsection{Advantage and Disadvantage of Technology}

There are many advantages to the use of technology, especially in the field of education. Skinner (1984) showed that using technology in instruction helps as twice as instruction without using Computer assisted instruction. Another close study by Papert (1972) predicted that there would be more stages of development in learning for pupils when they move from formal and strict environment of learning to a computer-assisted learning environment.

At the same time, using technology and IT in instruction provides the students with many cognitive abilities, which are:

- Accurate mental operations and discipline of optimum thinking as well as effective expression and good explanation of sentences that have similarity to the language of the computer.

- Development of overall concepts such as variable transforming function, hypothetical-deductive rationale and formal proceeding.

- Solving problems from any area through making use of the heuristic strategies.

\section{Theoretical Background}

Garavan and Morely (2006) state that training contribution has some underlying ongoing ambiguities. Neverthless, Ortlieb and Hirt (2012) called on for the potential outcomes of a performance and strategic orientation. Orlieb (2012) points out that trainings can help effectively in achieving competitive advantage through the development of competencies, specific skill sets and knowledge creation if they are planned in a strategic way. (Grossman \& Salas, 2011) also state that the employees have to develop their own skills and adapt to the changes of work in order to improve their performance. Hence, training is essential for successful business processes because it is an enabling component that leads to acquisition of knowledge.

\subsection{Key Strategies Training for Individual Psychotherapy}

Norcross (2005) states that this theory of integration includes the establishment of a conceptual framework that leads to the top and the optimum elements of two or more approaches of theory. The theoretical framework is based on the existence of a relationship between seven theories of psychotherapy (Brooks-Harris, 2008). It also concentrates on theories of behavioral therapies, emotion -focused and cognition.

\subsection{Resource-Based View Theory}

Galbreath (2005) states that one of the most widely discussed theories in literature in the past few years is the RBV theory and this theory can be traced back to Wenerfelt (1984) who stated that the success of the theory is due to the internal resources of the firm.

Barney (1991) the theory entails that it includes a number of resources, which contribute differently to the value of the firm. Barney (1991) states that the resources include the firm's brand name, capital equipment, reputation of the firm workers, knowledge and skills. It was also found out that the resources of the firm work as the most essential factor in accomplishing the sustainable competitive advantage of the firm.

Moreover, the resource-based View theory emphasizes the relationship between the firm capabilities and the present opportunities. The theory is described by Makadok (2011) as one that takes into consideration the 
complete use and utilization of the resources of the firm for the development of the core competencies and finally to carry out and achieve the competitive advantage of the firm. As a result, Barney, 1986; Russo and Fouts, 1997 state that the competitors will be away behind the performance of the firm if many factors exert work towards the use of the information resources, human abilities and internal strategies. Thus, organizations have to strengthen and maintain the relationship between the internal capabilities of the firm and its external environment to overcome the competitors and achieve the competitive advantage.

Other similar studies examined the topic and showed that technology is one of the most essential resources of the companies that contribute effectively to the achievement of the competitive advantage and creating a positive relationship with the performance of the firms. Many other studies stated that both training and technology have a positive effect on the performance of the firms.

Overall, previous studies revealed that the selected study variables are regarded as the resources of competitive advantage and thus the most suitable underpinning theory that can be used and employed is the RBV theory.

\section{Knowledge-Based View Theory}

The rise of knowledge perspective on several strategic topics occurred in the past several decades. These strategic topics of research included transfer of capabilities, alliances, acquisitions and product development. Knowledge-based view theory is one of these strategies and it is the main focus of the current study. Grant (1996) states that knowledge is considered one of the strategic resources of the company.

In addition, more research in literature shows that Knowledge-based view theory is described as the resources based thinking view as the resource used are related to both knowledge-based resources and the intangible assets . However, there are other studies that emphasize on the usefulness of the theory in extending the theory and learning of the organization to the strategy used. Spender (1996) states that knowledge is defined as the continuous social development, unlike to a resource. In brief, the knowledge based theory can be utilized as the current study taking into consideration the purpose and the variables of the study. The purpose of the study is to examine the how the strategy control plays a vital role in the improvement of the performance of the organization. Consequently, training, technology and SM can be used. Kogut and Zander (1992) Knowledge-based View theory is an extension organizational learning to strategy. This views knowledge as the most important resource of the company. It is essential because it helps to understand the alliances and the strategy of the company. in addition, Reus et al.'s (2009) states that it is suitable to think of the internal knowledge in case of the external knowledge that is related to the environment of the company to improve its performance as KBV theory implies. Hence, it is suitable to use the KBV theory in examining the variables of this study.

\section{Framework Development}

The current study was carried out through reviewing literature and previous studies to propose and develop some hypotheses. The proposed hypotheses are about the existing relationship between it management, strategy management and training on one side and the organizational performance on the other side. It was found out that the three variables assisted the organizational performance. To explain more, IT management, strategy management and training proved to have a positive impact on the overall performance of the organizations. The framework of the study included IT management, strategy management and training on the organizational performance. The hypotheses that are used in the study are as follows:

H1: Organizational performance is positively affected by training.

$\mathrm{H} 2$ : Organizational performance is positively and significantly affected by strategy management.

H3: Organizational performance is positively and significantly affected by strategy management. 


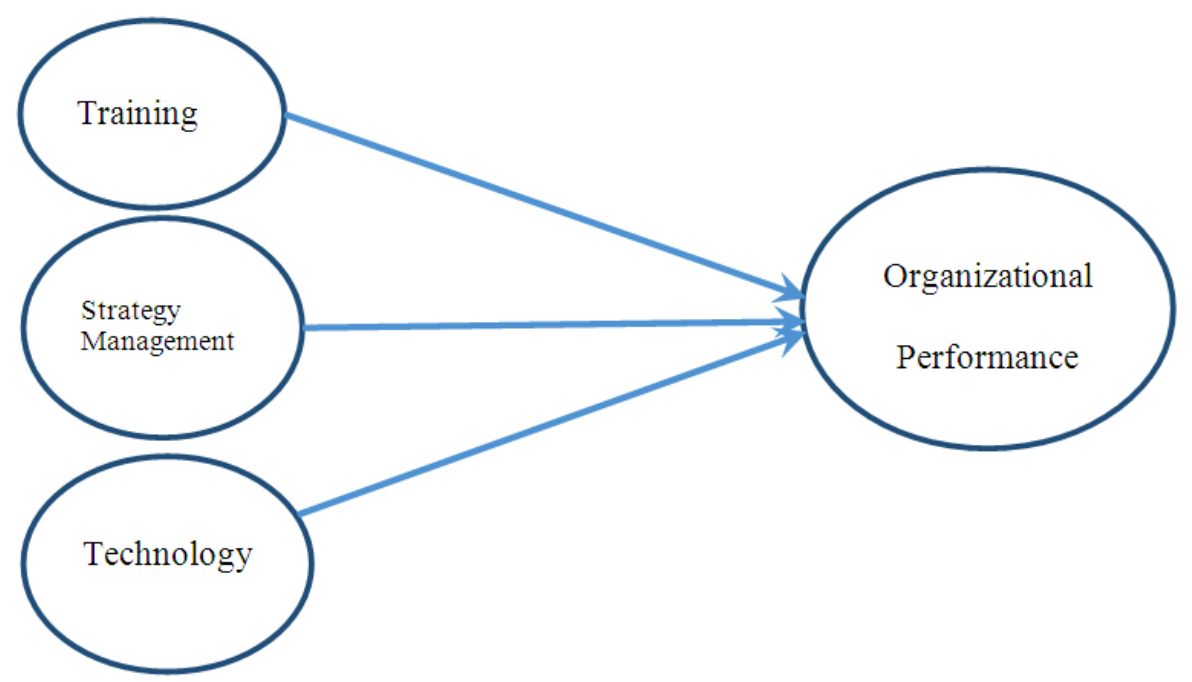

Figure 1. Research Framework

\section{Methodology}

The aim of the current study is to examine the effect of the variables on the organizational performance. The framework of the study is to measure the impact of information technology and training on the performance of an organization in the Sharjah Police department in the UAE.

There are five departments in the Sharjah Police. These five departments are Deputy Commander in Chief, general Administration resources and support services, general Commander, general directorate of central operations, General Directorate of Police Operations. The mentioned departments were later divided into 21 main departments that included 255 branches and 86 head sections. Each section is led by a head section officer that leads the employees and is responsible for carrying out certain tasks.

Zikmund (2003) stated that the four main research methods for the descriptive and casual studies included observation, secondary data $\mathrm{m}$ survey and experiment. The study focused on collecting data through survey method that makes use of interview or survey questionnaire from the participants through the internet, mail, personal / self-administered questionnaire, and the telephone.

The main aim of the current study is to provide a valid and dependable framework for the relationship between the organizational performance and IT management, strategy management and training in the case of the Sharjah Police in the UAE.

\subsection{Variables and Instrumentation Measurement}

The current study used the literature review to gauge the variables of the study and it used items to be in context with the study sample and the local setting. Organizational excellence is the dependent variable in the study and the independent variables are the customer focus and the strategic planning. Organizational culture is one of the main factors that was considered in the study.

\subsubsection{Measurement of Training}

The study used a 5-point likert scale ranging from 1 (strongly disagree) to 5 (strongly agree) and adopted Ubeda-Garcia, Maro-Lajara, Sabater-Sempere and Garcia-Lillo (2013).

According to (Kaplan \& Norton, 1996), BSC stands for the balanced Score Card and it functions as a management system that is new and it is used in the business strategy to reduce the gap implementation and strategy development. The items used in this study are taken from previous studies studies by Cragg, Mills and Suraweera (2013). These previous studies used a 5-point Likert scale ranging from 1 to 5 . The main goal of the study is the organizational performance. The current study the dependent variable is the organizational performance and how it is affected by the training and It management.

\section{Data Analysis}

The researcher entered the data collected from the Sharjah Police in SPSS program to analyze the data and obtain the results. The main outcomes of this study are explained in the following tables. 
In the first table (table 1), the descriptive analysis of the study is provided. The table contains the descriptive analysis that was used to describe it management, training and performance of the organization from the answers provided by the participants.

As shown in Table 1, 1.00 was the minimum value of all the constructs whereas 5.00 was the maximum value that represents the Likert scale. In addition, the maximum mean value was 3.927 with the lowest standard deviation at 0.687 . The results of the study show that training was one of the main priorities of the head sections in all the departments of the Sharjah police to improve the organizational performance and reach its highest levels. The study also showed that the mean and the standard deviation of the IT management were 3.420 and 1.002. The standard deviation is regarded as the highest. The results of the data collected stressed the importance of it management. As for the organizational performance the standard deviation was 0.885 and the mean value was 3.493 .

Table 1. Descriptive Statistics of the Constructs

\begin{tabular}{cccccc}
\hline Construct & N & Minimum & Maximum & Mean & Std. Deviation \\
\hline Training & 245 & 1 & 5 & 3.927 & 0.687 \\
Strategy Management & 245 & 1 & 5 & 3.602 & 0.823 \\
IT Management & 245 & 1 & 5 & 3.420 & 1.002 \\
Organizational Performance & 245 & 1 & 5 & 3.493 & 0.885 \\
\hline
\end{tabular}

\section{Correlation Analysis}

The statistical method that is used to provide definition of the direction and the strength of the linear relationship between the two variables is the correlation analysis. It measures both the importance of the variables relationship and the strength of the correlation analysis. The researcher deployed bivariate association to obtain this level of correlation and it used Pearson's coefficient of correlation. This technique involved a value that ranges from -1 to +1 that shows the correlation strength between the two variables of the study.

The significant correlation that existed the two variables is confirmed in the correlation analysis. The level of the strong correlation is 0.01 . The value of correlation between strategy management and training was tabulated in table 5.4 and it is indicated at 0.793 . It also indicates $79 \%$ of the relationship between the variables of the study.

Table 2. Correlation of variables

\begin{tabular}{clcccc}
\hline \multicolumn{2}{c}{ Construct } & Training & $\begin{array}{c}\text { Strategy } \\
\text { Management }\end{array}$ & IT Management & $\begin{array}{c}\text { Organizational } \\
\text { Performance }\end{array}$ \\
\hline Training & $\begin{array}{l}\text { Pearson } \\
\text { Correlation } \\
\text { Strategy Management }\end{array}$ & $\begin{array}{l}\text { Pearson } \\
\text { Correlation }\end{array}$ & $.793^{* *}$ & 1 & \\
IT Management & $\begin{array}{l}\text { Pearson } \\
\text { Correlation }\end{array}$ & $.697^{* *}$ & $.806^{* *}$ & 1 & 1 \\
Organizational Performance & $\begin{array}{l}\text { Pearson } \\
\text { Correlation }\end{array}$ & $.656^{* *}$ & $.830^{* *}$ & $.727^{* *}$ & 1 \\
\hline
\end{tabular}

**. Correlation is significant at the 0.01 level (2-tailed).

\section{Regression Analysis}

Multiple regression analysis is used to find out the correlations between the several independent variables and the constant dependent one. The study made use of several approaches in the multiple regression analysis and this included stepwide regression, hierarchial or sequential regression and standard regression (Pallant, 2001). In order to provide its outcomes, the study used multiple regressions to enhance the results and the answers that are collected and also to test the hypotheses that are proposed in the study.

It is clear in table 3 that that correlation between the variables is 0.534 . This is considered a high correlation. This shows the reliability and the consistency that exists between the variables in order to achieve the objectives of the study.

Table 3. Analysis of Direct Hypotheses

\begin{tabular}{ccccccc}
\hline Hypothesis & Relationship & Path & SE & T-value & P-value & Decision \\
\hline H1 & Training ------> OP & -0.041 & 0.076 & -0.547 & 0.585 & Not Supported \\
H2 & Strategy Management --------> OP & 0.77 & 0.077 & 10.063 & 0.000 & Supported \\
H3 & IT Management -------> OP & 0.152 & 0.053 & 2.844 & 0.005 & Supported \\
\hline
\end{tabular}

$*: \mathrm{p}<0.05 ; * *: \mathrm{p}<0.01 ; * * * \mathrm{p}<0.001$ 


\section{Discussion and Conclusion}

The purpose of the current study was to examine the impact of both information technology management and training on the performance of the organization. The previous sections explained the relationship that exists between the variables of the study.

\section{Strategy Management Effect on Organizational Performance}

The study concluded that there is a relationship between the variables of the study. The results showed significant and positive effect $(\beta=0.770 ; \mathrm{t}=10.063 ; \mathrm{p}<0.01)$, that is in alignment with the results of previous studies of the same caliber (e.g., Nilsson \& Olve, 2001; Thomas, 2007; Bourne et al., 2000; Kaplan \& Norton, 2007).

\section{IT Management Effect on Organizational Performance}

The study showed that there is a significant and positive correlation between the two variables of the study ( $\beta=$ $0.152 ; \mathrm{t}=2.844 ; \mathrm{p}>0.5$ ) and this result supports the previous studies that indicated the same finding of the study (e.g., Cantoni, Cellario \& Ports, 2004; Kumar \& Suneja, 2011).

Overall, the Police department of Sharjah is considered one of the main priorities in the development of the UAE. Hence, the Sharjah Police department contributes effectively in realizing the objectives and the goals of the UAE. According to the previous studies, It management, strategy management and training are three main factors and effective strategies that effectively improve the performance of the organization and enhances the competitive advantage of the firms.

The results of the study supported the hypotheses of the study and they were either rejected or confirmed regarding the performance of the organization and how it is affected by IT management, strategy management and training.

Eventually, the results of the study and its findings were collected from the Sharjah Police and particularly from the units of its head sections. The data was collected from the top personnel because they have enough experience and knowledge regarding the impact of the variables of the study on the organizational performance. Regarding this, in the future other studies can follow a different perspective through getting relevant data from the concerned employees and other customers.

\section{References}

Barney, J. (1986). Organizational culture: can it be a source of sustained competitive advantage? Academy of Management Review, 11, 656-665. https://doi.org/10.5465/amr.1986.4306261

Barney, J. B. (1991). Firm resources and sustained competitive advantage. Journal of Management, 17(1), 99-120. https://doi.org/10.1177/014920639101700108

Berg, G. V., \& Pietersma, P. (2014). The 8 Steps to Strategic Success: unleashing the power of engagement. London, UK: Kogan Page Li Boselie, P., Dietz, G., \& Boon, C. (2005).

Bergh, D. D., \& Lim, E. N. K. (2008). Learning how to restructure: absorptive capacity and improvisational views of restructuring actions and performance. Strategic Management Journal, 29(6), 593-616. https://doi.org/10.1002/smj.676

Brush T. (2007). Integrating technology into K-12 teaching and learning: current knowledge gaps and recommendations for future research. Education Tech Research Dev, 55, 223-252. https://doi.org/10.1007/s11423-006-9022-5

Burns, B. D., \&Holyoak, K. J. (1996). Theimpact of goal specificity on strategy use and the acquisition of problem structure. Cognitive Science, 20, 75-100. https://doi.org/10.1207/s15516709 $\operatorname{cog} 2001 \_3$

Campbell, J. (1971). Personnel training and development. Annual Review of Psychology, 22(1), 565-602. https://doi.org/10.1146/annurev.ps.22.020171.003025

Carroll, G. (1984). "Dynamics of publisher succession in newspaper organizations". Administrative Science Quarterly, 29(1), 93-113. https://doi.org/10.2307/2393082

Chi, M. T. H. (2006). Two approaches to the study of experts' characteristics. In K. A. Ericsson, N. Charness, R. R. Hoffman, \& P. J. Feltovich (Eds.), Cambridge handbook of expertise and expert performance (pp. 21-30). Cambridge, England: Cambridge University Press. https://doi.org/10.1017/CBO9780511816796.002

David, F. R. (2007). Strategic management: Concepts \& cases. Prentice Hall. New York. 11 th Edition.

De Waal, A. D. (2010). Achieving high Performance in the Public Sector What needs to be Done? Public Performance \& Management Review, 34(1), 81-103. https://doi.org/10.2753/PMR1530-9576340105 
De Waal, A., \& Kerklaan, 1. (2004). De result aatgerichte overheid. Op weg naar de prestatiegedreven overheidsorganisatie [the results-oriented government. toward performance-driven gov ernment organization].

Demirbag, M., Koh, S. C., Tatoglu, E., \& Zaim, S. (2006). TQM and market orientation's impact on SMEs' performance. Industrial Management \& Data System, 106(8), 1206-1228. https://doi.org/10.1108/02635570610710836

Dewberry, C. (2001). Performance disparities between whites and ethnic minorities: Real differences or assessment bias? Journal of Occupational and Organizational Psychology, 74, 659-673. https://doi.org/10.1348/096317901167578

Galbreath, J. (2005). Which resources matter the most to firm success? An exploratory study of resource-based theory? Technovation, 25, 979-987. https://doi.org/10.1016/j.technovation.2004.02.008

Grusky, O. (1963). "Managerial succession and organizational effectiveness". American Journal of Sociology, 69(1), 21-31. https://doi.org/10.1086/223507

Jing, F. F., \& Avery, G. C. (2008). Missing Links in Understanding the Relationship between Leadership and Organizational Performance. International Business \& Economics Research Journal, 7(5), 67-78.

Johnson, G., Whittington, R., \& Scholes, K. (2011). Exploring Strategy (Ninth ed.). London, UK: Pearson.

Johnson, H. (1983). The search for gain in markets and firms: a review of the historical emergence of management accounting systems. Accounting, Organizations and Society, 2(3), 139-184. https://doi.org/10.1016/0361-3682(83)90021-1

Kanji, G., \& Sá, P. (2007). Performance measurement and business excellence: the reinforcing link for the public sector. Total Quality Management \& Business Excellence, 18(1-2), 49-56. https://doi.org/10.1080/14783360601043096

Kaplan, R. S., \& Norton, D. P. (1992). The Balanced Scorecard - Measures that Drive Performance. Harvard Business Review, 70-79.

Koch, R. (2011). Strategy: How to create, Pursue and deliver a winning strategy (Fourth ed.). Edinburgh Gate, UK: Pearson Education Ltd.

Kraiger, K. (2003). Perspectives on training and development. John Wiley \& Sons, Inc. https://doi.org/10.1002/0471264385.wei1208

Kraiger, K., McLinden, D., \& Casper, W. (2004). Collaborative planning for training impact. Human Resource Management, 43, 337-351. https://doi.org/10.1002/hrm.20028

Matloff, M. (1996). AMERICAN MILITARY HISTORY - Volume 1: 1775-1902. United Kingdom: Combined Books Pennsylvania. Mckeown, M. (2012). The Strategy Book. Edinburgh Gate: Pearson Education Limited.

Niven, P. R. (2006). Balanced Scorecard Step by Step: Maximizing Performance and maintaining results (Second ed.). New Jersey: John Wiley @ Sons.

Norton, D. P. (1992). The Balanced Scorecard - Measures that Drive Performance. Harvard Business Review, 70-79.

Norton, D. P. (2004). Strategy Map : converting intangible assets into tangible outcomes. Boston, US: Harvard Business School Publishing Corporation.

Outram, C. (2013). Making your strategy work: how to go from paper to people. Edinburgh Gate, UK: Pearson Education Limited

Ptacek, J. (ed) (2010). Restorative justice and violence against women. New York, N.Y.: Oxford University Press.

Sink, D., \& Tuttle, T. (1989). Planning and measurement in your organization of the future. Norcross: GA: Industrial Engineering and Management Press.

Sisson, K. (1993). In search of HRM. British Journal of Industrial Relations, 31(2), 201-210. https://doi.org/10.1111/j.1467-8543.1993.tb00389.x

\section{Copyrights}

Copyright for this article is retained by the author(s), with first publication rights granted to the journal.

This is an open-access article distributed under the terms and conditions of the Creative Commons Attribution license (http://creativecommons.org/licenses/by/4.0/) 